\title{
The Moderating Effect of Organization Culture on Competition Intensity and Hospital Quality
}

\author{
Tor Guimaraes, Tennessee Tech University, USA \\ Maria do Carmo Caccia-Bava, University of Sao Paulo, Brazil \\ Melissa Geist, Tennessee Tech University, USA
}

\begin{abstract}
This study empirically tests the relationship between hospital competition intensity and its quality, and the moderating impact of hospital culture on this relationship. An emailed questionnaire collected data from 239 American hospital CEO's to validate the measures and test the hypothesized relationships. The results corroborated the importance of competition intensity as determinant of hospital quality and the positive moderating impact of hospital organization culture as measured here. Future research should expand this model to include other potential determinants of hospital quality such as economic conditions and hospital size. Also, future research should explore other potential moderators and mediators for inclusion in a more elaborate model. While hospitals administrators cannot control the intensity of their competition, and are forced to do everything they can to improve hospital quality (including establishing a helpful organization culture), understanding how to measure these constructs and manage their relationships should be very useful.
\end{abstract}

\section{INTRODUCTION}

Compared to patients' desire for hospital care quality, at the provider organization level, the enthusiasm for hospital quality seems somewhat reduced. There are numerous studies addressing the determinants of hospital quality (Missios \& Bekelis, 2018; Montgomery et al., 2013; Stimpfel et al., 2016). Some studies focusing on hospital Board level managers indicate a low prioritization of hospital quality issues on the Board's agenda and not all hospitals have quality on their agenda (Jha \& Epstein 2010; Joshi \& Hines, 2006). Some studies reported that quality issues were not consistently and sometimes never addressed (Mastal et al., 2007; Prybil et al., 2010). Many studies addressing Board time spent on quality and patient safety, reported that less than half of the total time was spent on such issues (Baker et al., 2010; Jha \& Epstein, 2010; Jiang et al., 2008; Jiang et al., 2009; Levey et al., 2007; Prybil et al., 2010) and a majority of Boards reported spending $25 \%$ of their time or less on hospital quality issues (Baker et al., 2010; Jha \& Epstein, 2010; Jiang et al., 2009; Poniatowski et al., 2005; Prybil et al., 2010; Vaughn et al., 2006).

Similar to health care quality, the importance of competition in any business sector is also widely recognized. Competition can be defined as the process of controlled rivalry between firms striving to make sales and profits. Without competition, an organization has little incentive to lower prices or improve its products and services. Among hospitals, competition has been found to have a healthy

\section{DOI: 10.4018/IJHISI.2020070103}

This article, originally published under IGI Global's copyright on March 13, 2020 will proceed with publication as an Open Access article starting on January 14, 2021 in the gold Open Access journal, International Journal of Healthcare Information Systems and Informatics (converted to gold Open Access January 1, 2021), and will be distributed under the terms of the Creative Commons Attribution License (http:// creativecommons.org/licenses/by/4.0/) which permits unrestricted use, distribution, and production in any medium, provided the author of the original work and original publication source are properly credited. 
effect in hospital performance. Seiler et al. (2015) analyzed the causal impact of competition on managerial quality and hospital performance including quality. They found that higher competition results in higher management quality and improved hospital performance.

Last, organization culture has been considered important for company prosperity by many authors since the early 1980s (Peters \& Waterman, 1982; Davis, 1984). According to Büschgens et al. (2013), the literature was based on two major propositions: first, cultures reflect the values and actions of the senior leaders; second, cultures are important determinants of firm performance.

Based on the importance of these three areas, the primary objectives of this study are to empirically test the relationship between hospital competition intensity as a determinant of hospital quality, and the moderating impact that hospital culture is likely to have on this relationship. The next section discusses the proposed model in greater detail, its main constructs, and the justification for the two proposed hypotheses.

\section{THEORETICAL BACKGROUND}

\section{Dependent Variable: Hospital Quality}

The importance of hospital quality and reliability has been well established (Chassin \& Loeb, 2013) at the national level by the creation of The Joint Commission, which accredits and certifies nearly 21,000 health care organizations and programs in the United States. The Commission's stated mission is to continuously improve health care for the public, in collaboration with other stakeholders, by evaluating health care organizations and inspiring them to excel in providing safe and effective care of the highest quality and value. According to Mark Pelletier, The Joint Commission's Chief Operating Officer of Accreditation and Certification Operations, in 2017 they surveyed 750 U.S. hospitals from Jan. 1 through June 30, found deficiencies at every hospital during each of the surveys, and worked with these hospitals to address the issues. Immediate Threats to Health and Safety (ITHS) findings are dependent on a combination of factors and findings. If surveyors identify a deficiency at this level, they immediately contact their central office staff to confirm the ITHS status, review the finding with hospital leadership, support hospital leadership and staff in mitigating the threat while they remain on site, expect that the hospital will identify the source(s) of the ITHS, notify the Centers for Medicare \& Medicaid Services (CMS) which determines any appropriate regulatory action, and if necessary share findings with the state department of health which determines if the ITHS requires public action.

Another major attempt at improving hospital quality comes from the American Nurses Credentialing Center (ANCC) with the implementation of the Magnet Recognition Program (ANCC, 2017; Chen et al., 2014; Stimpfel et al., 2016). While the results from Magnet Programs implementations have been controversial (Lasater et al., 2016; Missios \& Bekelis, 2018) for a variety of reasons (i.e. Magnet program is too short lived or not fully implemented, results are measured in different ways, etc.), their underlying strong motivation is the importance of improving hospital care quality through nursing activities and better management in this critical area (The Truth about Nursing, 2016; Missios \& Bekelis, 2018; Park et al., 2016; Stimpfel et al., 2014).

A similar example of national recognition of the importance of hospital quality in the European Union is The European Observatory on Health Systems and Policies (EOHSP), which promotes and supports the establishment of quality improvement policies. It tries to accomplish its mission by bringing together a wide range of policy makers, academics, and practitioners for analyzing trends and drawing on European experiences regarding health quality policy implementation issues. The EOHSP is a partnership between the World Health Organization Regional Office for Europe, the Governments of Belgium, Finland, Greece, Norway, Slovenia, Spain and Sweden, the Veneto Region of Italy, the European Investment Bank, the Open Society Institute, the World Bank, the London School of Economics and Political Science, and the London School of Hygiene \& Tropical Medicine. 
Many studies of hospital quality have been forced to consider hospital quality from a broader perspective and include other essential factors such as patient satisfaction, friendly administrative requirements, hospital layouts conducive to operating efficiency, etc. Lasater et al., (2016) found that hospitals known for nursing excellence performed better in terms of value-based measures and also in terms of patients' experiences (Stimpfel et al., 2016).

Parand et al. (2014) did an extensive survey of the literature addressing the role of hospital managers in quality and patient safety. As discussed earlier, some studies on hospital Board level managers indicate a low prioritization of hospital quality issues on the Board's agenda and not all hospitals have quality on their agenda (Jha \& Epstein 2010; Joshi \& Hines, 2006). Other studies reported that quality issues were not consistently and sometimes never addressed (Mastal et al., 2007; Prybil et al., 2010). Thus, we must conclude that while quality of care among hospitals is widely recognized as a critical variable, we need a greater understanding of its determinants, its outcomes, and the potential mediating and moderating variables.

\section{Independent Variable: Competition Intensity}

As mentioned earlier, competition is the driving force behind efficient and fair markets, which are essential for enabling private sector development and economic growth. One of the best indications of importance is the wide variety of ways researchers have devised to measure the level of competition in practice. A major survey by Kwiecinski (2017) discussed the pros and cons of various measures for company competition intensity. At the company level, in the short term most organizations might prefer less competition. However, in the long term competition is expected to have a generally salutary effect for organizations as well as society. Thus, the ultimate goal of antitrust laws is to protect consumers' purchasing power and save jobs and businesses. Short term limiting competition might provide higher profits by increasing prices or reducing quality, thus hurting consumers. Such a situation is likely to attract new competitors from outside the market, which can drive the now inefficient and weak sellers out of business resulting in job losses.

Specifically, competition among hospitals has also been found to have a healthy effect on hospital performance (Bloom et al., 2015; Everhart et al., 2013). Seiler et al. (2015) studied the impact of competition on management quality and performance. The research measured the management quality of 100 public hospitals through a survey of clinicians and managers, and used data published by the government to assess the performance of NHS hospitals in England. They found that higher competition results in higher management quality and improved hospital performance. Adding a rival hospital increases management quality by 0.4 standard deviations and increases survival rates from emergency heart attacks by $9.7 \%$.

Thus, more hospital competition leads to improved hospital management and higher hospital performance in terms of quality, productivity, and staff satisfaction. Management quality is linked to improved indicators of hospital performance including clinical quality, mortality rates, and staff turnover rates. Hospitals with higher management scores also had shorter waiting times, lower MRSA infection rates and performed better financially. Based on this evidence we propose hypothesis H1: Hospital Competition Intensity is directly related to Hospital Quality.

\section{Moderating Variable: Organization Culture}

While the importance of organization culture has a strong intuitive appeal as a determinant of company innovativeness and performance, from the beginning researchers have had difficulties producing conclusive results, let alone being able to make effective recommendations to practitioners about how to change their company culture to improve innovativeness. Ogbonna and Wilkinson (2003) have recognized some difficulties with the body of research on the organization culture, innovativeness, and performance links. They posit that, similar to the organizational behavior literature, some researchers in the human resources area question the importance of the culture concept and the wisdom of planned 
culture change. However, despite academic research confusion, organization managers remain highly interested in managing their organization culture.

Many authors in the early 1980s were proposing that company culture was important for company prosperity (Davis, 1984; Peters \& Waterman, 1982). According to Büschgens et al. (2013), the literature was based on two major propositions: first, cultures reflect the values and actions of the senior leaders; second, cultures are important determinants of organization performance. More recently, Schneider, Ehrhart, and Macey's (2013) survey of the literature about organizational culture showed little empirical evidence for these assumptions.

Similarly, in the context of the organization culture-performance relationship, researchers have had conceptual difficulties defining culture (Schneider et al., 2013), and experienced methodological issues due to small sample sizes, construct measurement issues, and variance created by trying to compare multi-industry assessments (Detert et al., 2000). Even though the academic research on culture has become more sophisticated methodologically, individual researchers have used diverse measures of company culture and performance, making cross studies comparisons more difficult (Hartnell et al., 2011; Sackmann, 2011;).

If a company's innovativeness is intuitively linked to company culture, why have researchers not been able to conclusively demonstrate this link? Büschgens et al. (2013) provided some possible reasons. First, many firms well known to produce and commercialize new products and services become superficially known for some unique aspect of their corporate culture, so $3 \mathrm{M}$ explains its innovativeness as being essentially a science-based organization, and. Apple's innovativeness comes from promoting the idea of employees focusing on larger product visions leading to the creation of new major ground-breaking technologies. Much of Google innovativeness is credited to its employees' individuality and broad freedom. This superficial analysis of existing cultural traits, which have led to successful innovativeness, is misleading because it is widely known today that company innovativeness will require more than one cultural trait no matter how important. This adds to the confusion and represents the other side of the spectrum where a very large number of culture traits have been shown in the literature discussed next as being mostly empirically irrelevant as determinants for company innovativeness.

Further, as stated by Büschgens et al. (2013), "the heterogeneity of culture in practical examples is mirrored by a multitude of cultural values that has been investigated scientifically." In their literature review they identified more than 40 different cultural traits supposedly related to company innovativeness, comprising a wide range of broad variables such as "innovation culture" (Chandler et al., 2000; Gumusluoglu and Ilsev, 2009) or "supportive culture" (Abbey and Dickson, 1983; Berson et al., 2008; Wei and Morgan, 2004) to very specific cultural traits like tolerance for failure (Danneels, 2008) or participative decision-making (Hurley \& Hult, 1998). Some confusion is likely to emanate from the wide diversity of traits being investigated, if one assumed a positive cultureinnovation relationship. Some studies assuming a positive culture-innovation relationship produced counter intuitive results, showing negative correlations for "supportive culture" (Berson et al., 2008) and culture stability (Jaskyte, 2004). Given the confusion about the various interpretations, their measurements, and relationships to company innovativeness and performance, Büschgens, Bausch, and Balkin (2013) stated, "a compelling theoretical explanation for the relation of organizational culture and organization innovativeness or performance is still missing."

Nevertheless, Parand et al. (2014) extensive survey of the literature addressing the role of hospital managers in quality and patient safety showed some studies whose results linked hospital quality to organization culture. Activities aimed at enhancing patient safety culture emerged from several studies across organizational levels (Bradley et al., 2003; Levey et al., 2007; Saint et al., 2010; Weingart and Page, 2004).

Board and senior management's activities included encouraging a quality oriented organizational culture on norms regarding interdepartmental and multidisciplinary collaboration, and advocating quality-oriented efforts to clinicians and fellow senior managers, providing powerful messages of 
safety commitment and influencing the organization's patient safety mission (Bradley et al., 2003; Weingart and Page, 2004).

Managers at differing levels in some hospitals focused on cultivating a culture of clinical excellence and articulating the organizational culture to staff (Saint et al., 2010). Factors to motivate/ engage middle and senior management in quality efforts included senior management commitment of resources and managerial accountability (Bradley et al., 2006; Balding, 2005). Some studies also revealed connections between senior management and Board priorities and values with hospital performance. Ensuring hospitals capacity for high-quality standards such, as physician credentialing was identified as a Board managers' responsibility in more than one study (Jiang et al., 2009; Levey et al., 2007), thus indicating a potential link between hospital culture and quality. Furthermore, the concept of magnet hospital proposed and implemented by the American Nurses Credentialing Center (ANCC) underlies the importance of hospital culture as an important determinant of quality (ANCC 2017). Montgomery et al., (2013) have proposed a link between hospital culture, burnout, and quality of care. Last, while there are some conflicting results, some studies have shown a link between environment and various measures of hospital quality (Chen et al., 2014; Lasater et al., 2016; Stimpfel et al., 2016).

Based on the discussion above and because organization managers remain highly interested in better understanding their organization culture, we propose a second hypothesis H2: Hospital culture will enhance the relationship between competition intensity and hospital quality.

\section{STUDY METHODOLOGY}

This section provides an overview of the data collection procedure, a brief description of the sample, a detailed discussion of how the variables were measured, and the data analysis procedures.

\section{Sampling and Data Collection}

This field test used an emailed questionnaire to collect data from the hospital CEO (Chief Executive Officer) of 1000 randomly selected hospitals from a list of approximately 6,000 in a US hospital directory. The email cover letter to the CEO explained the purpose of the study, assured that all information would be held in the strictest confidence and only summary information from all participants would be published, asked for email response to the questionnaire, and offered to share this study's results. As a courtesy, attached to the letter was a published report from a previous study regarding success factors for hospital processes reengineering projects. Approximately 60 percent of the CEOs approached did not respond to the initial call for participants. From those who responded, 53 CEOs responded declining to participate for a wide variety of reasons, and 349 CEO's expressed willingness to participate in the study thru email. The researchers targeted the CEO position because they are likely to be most aware from a corporate perspective of their hospital activities regarding the issues relevant to this study: culture, quality, competition, etc. Furthermore, the group is relatively homogeneous (must deal with operational and strategic issues, represent the entire organization, able to address the constructs important to this study), a characteristic that strengthens internal validity of the data collection instrument used in the study. The CEO or their assistants returned 283 emailed questionnaires in time to be included for data analysis, however 44 were discarded due to incomplete information or because they were hospital personnel whose titles were deemed significantly below strategic management, thus producing a usable sample size of 239 responses.

\section{Sample Description}

The sample demographics for the hospitals in this field test are presented in Tables 1 and 2. The sample shows good representation based on hospital geographical area and size (number of beds). The 239 usable questionnaires provide a response rate, which is acceptable for studies of this type (Teo \& King, 1996), and consistent with past experience with mailed surveys (George \& Barksdale, 1974; 
Table 1. Hospital geographical area

\begin{tabular}{|l|c|c|}
\hline \multicolumn{1}{c|}{ US Geographical Area } & Frequency & $\%$ \\
\hline Southwest & 53 & 22.18 \\
\hline Southeast & 44 & 18.41 \\
\hline Central & 38 & 15.90 \\
\hline Northwest & 53 & 22.18 \\
\hline Northeast & 51 & 21.34 \\
\hline Total & 239 & 100.00 \\
\hline
\end{tabular}

Table 2. Hospital size

\begin{tabular}{|l|c|c|}
\hline \multicolumn{1}{|c|}{ Number of beds } & Frequency & $\%$ \\
\hline 50 or below & 19 & 7.95 \\
\hline 51 to 100 & 32 & 13.39 \\
\hline 101 to 300 & 66 & 27.62 \\
\hline 301 to 500 & 68 & 28.45 \\
\hline 501 or above & 54 & 22.59 \\
\hline Total & 239 & 100.00 \\
\hline
\end{tabular}

Igbaria et al., 1991). Nevertheless, care was taken to assess the representativeness of the sample. To compare the sample against non-respondents, Chi-square tests were used to check for the possibility of non-response bias. The results of this test support the conclusion that based on organization size (number of beds) and geographical location; hospitals in the sample are not significantly different from those in the total population.

\section{Construct Measurement}

\section{Dependent Variable: Hospital Quality}

Depending on their perspectives and research questions, researchers have measured hospital quality in a wide variety of ways. The best measure depends on the study objective. Jha et al. (2007) and Lindenauer et al. (2007) measured hospital quality in terms of the specific clinical treatments methodically given by care givers to patients admitted for specific medical problems such as acute myocardial infarction, congestive heart failure, and pneumonia. Many other studies of hospital quality have had to expand the quality measure to include other essential factors such as patient satisfaction, hospital layouts conducive to operating efficiency, friendly administrative requirements, etc.

Gupta and Rokade (2016) conducted a major review of the literature on hospital quality measures to assess its importance. Sharma and Narang (2011) and Wilde-Larsson and Larsson (2009) discussed the importance of including patients' perceptions of service quality and willingness to return to the hospital. Verelst et al. (2012) measured hospital quality in terms of adverse events to hospital patients based on post facto retrieval of medical records. Seema Mehta (2011) measured patient satisfaction with hospital services including promptness of service, medical aid, clinical services, and available facilities. Bhardwaj and Chawla (2013) focused on patient perceptions and expectations and measured quality in terms of service accessibility, timeliness, accuracy, security, ambience, competence, impressiveness, and customization. As shown in Appendix A, for this study, we built our own measure 
of hospital quality using the broad parameters suggested by Gupta and Rokade (2016) based on their extensive survey of hospital quality measures.

\section{Independent Variable: Hospital Competition Intensity}

The pros and cons of various measures for company competition intensity were conveniently discussed in a broad survey by Kwiecinski (2017). The most appropriate measure to be used for any construct is dependent on the study objectives. To facilitate future inter-studies comparisons we chose a measure, which is most widely used among researchers and is easily understood and accepted by practitioners. Among the 23 publications based on questionnaires, the work by Jaworski and Kohli (1993) was cited by 57 percent of the studies. This measure contains 6 items addressing the organization's competition intensity experienced at the time. To those items, we added 3 items used by Lush and Laczniak (1987) which address managers' competition intensity expectations in the near future. The complete measure is shown in Appendix A.

\section{Moderating Variable: Hospital Organization Culture}

As discussed before, organization culture has been a difficult construct for researchers to define and study. It is widely accepted as an important factor for organization innovativeness and performance, but over the years, there has been much controversy surrounding the measures used for this construct. Büschgens et al. (2013) provided some possible reasons for these difficulties such as some companies have unique circumstances behind their innovativeness, a large number of potentially important cultural traits, etc. In addition, many firms well known for their ability to produce and commercialize new products and services have become widely, although superficially, known for some unique aspect of their corporate culture. These controversies demanded a new measure for company culture, which was developed by going to companies known as successful innovators and more carefully and systematically identifying the more important organization culture traits (Guimaraes et al., 2018). This measure (shown in Appendix A) has been used for this study.

\section{Construct Validity}

The constructs addressed in this research project and their measures have been used by prior studies, nevertheless several precautions were taken to ensure the validity of the measures in the context of this study. Many of the recommendations by Carmines and Zeller (1979) were followed. To ensure content validity, a thorough survey of the relevant literature was undertaken to understand the important aspects of each major variable and its components, and not neglect important dimensions of any variable.

To further reduce the possibility of any non-random error, the main source of invalidity (Carmines $\&$ Zeller, 1979, p. 15), a group of three hospital managers from different organizations reviewed the questionnaire for validity (measuring the phenomena intended: factors related to hospital quality and competition), completeness (including all relevant items), and readability (making it unlikely that questionnaire respondents will misinterpret a particular question). Some questions were reworded to improve readability; otherwise, the items composing each major variable remained as derived from the literature.

As proposed by Carmines and Zeller (1979), "construct validation focuses on the extent to which a measure performs in accordance with theoretical expectations" (p. 27). To ensure construct validity, the theoretical relationships between the constructs should have been previously established, and these relationships hopefully have been empirically supported by different studies over time. As discussed earlier in the Theoretical Background section and Construct Measurement section, the theoretical underpinnings of this study are relatively well established, with most of the items in each construct having been addressed before by several authors. 


\section{Construct Reliability}

Even though the constructs and their measures used here have been used before by other authors, their reliability was re-tested using Cronbach's alpha coefficient proposed by Carmines and Zeller (1979).

Several authors have proposed different acceptable levels for the reliability coefficient. For example, Nunnally (1978) suggested a coefficient of 0.50 or higher would suffice. Srinivasan (1985) and Magal et al. (1988) contended that when using a not validated data gathering instrument in exploratory research, a reliability coefficient of 0.5 or higher is acceptable. Van de Ven and Ferry (1980) posited that in this type of research even a value of 0.4 or higher would be sufficient. In our case, the reliability coefficients for all the factors were higher than 0.70 , which was proposed by Peterson (1994) as useful for studies that are more rigorous. As Table 3 indicates, the internal consistency reliability coefficients (Cronbach's alpha) for the scales used in this study are all well above the level of 0.50 acceptable for exploratory studies of this type (Nunnally, 1978).

Table 3. Correlations between major variables

\begin{tabular}{|l|l|l|l|l|l|l|}
\hline & \multicolumn{1}{|c|}{$\begin{array}{c}\text { No. of } \\
\text { Items }\end{array}$} & \multicolumn{1}{|c|}{ Mean } & \multicolumn{1}{|c|}{ Std Dev } & \multicolumn{1}{|c|}{$\mathbf{1}$} & $\mathbf{2}$ \\
\hline 1. Hospital Quality (1-7) & 9 & 3.94 & 1.26 & $(.77)$ & & \\
\hline 2. Competition Intensity (1-5) & 9 & 3.13 & 1.44 & $.55^{* *}$ & $(.83)$ & \\
\hline 3. Hospital Culture (0-6) & 14 & 3.35 & 1.67 & $.49^{* *}$ & NS & $(.81)$ \\
\hline
\end{tabular}

Numbers in parentheses diagonally) are Cronbach's alpha reliability coefficients.

NS means not significant, ${ }^{*}$ means $p<.05,{ }^{* *}$ means $p<.01$

\section{Results and Related Data Analysis Procedures}

The average and standard deviation for each item in the questionnaire were computed. Confirmatory factor analyses for the items in each main variable were conducted as the basis for their validation and as a prerequisite for assessing their internal reliability through the Cronbach's alpha coefficients presented within parentheses in Table 3.

The items comprising each major variable were subjected to a principal component analysis followed by a varimax (orthogonal) rotation to identify composite factors. To be included in a given factor the item is expected to load unambiguously (i.e., with one loading of 0.5 and no other loadings greater than 0.4), as suggested by Magal et al. (1988). As suggested by several researchers (i.e. Nunnally, 1978), the minimum eigenvalue for which a factor is to be retained was specified as 1.0. This procedure produced single factor solutions for the hospital quality and competition intensity. Hospital culture items loaded unambiguously into the four factors as expected (Guimaraes et al., 2018). Since these factors are not useful for this study's objective, a second order factor analysis of these four factors produced a single factor representing hospital organization culture, which can be used to validate the results from this study.

To assess the moderating impact of hospital culture on the relationship between hospital competition intensity and hospital quality, we followed a data analysis technique which has been recommended as preferable to subgroup analysis for testing moderator effects because it makes more complete use of the data and its interaction effect (with the independent variable) on the dependent variable (Peters \& Champoux, 1979; Peters et al., 1984; Zadeck, 1971). First, hospital quality was regressed on competition intensity. The moderating variable (hospital culture) was added to the regression equation, and the increment in $\mathrm{R}^{2}$ (and the level of significance associated with the change) was computed. Once the significant relations were identified, the beta coefficients were computed to assess the direction of the relationship. The results are presented in Tables 4 and 5. 
Table 4. Moderated multiple regression results (dependent variable: hospital quality)

\begin{tabular}{|l|l|l|}
\hline Independent Variable: & \multicolumn{1}{|c|}{ Competition Intensity } & \multicolumn{1}{|c|}{ Incremental $\mathbf{R}^{2}$} \\
\hline \multicolumn{2}{|c|}{ Moderator: Hospital Culture } & $.30^{* *}$ \\
\hline & Competition Intensity & $.14^{* *}$ \\
\hline & + Hospital Culture & $.12^{* *}$ \\
\hline & $\begin{array}{l}+ \text { Hospital Culture } \mathrm{x} \text { Competition } \\
\text { Intensity }\end{array}$ & $.56^{* *}$ \\
\hline
\end{tabular}

${ }^{*} p<=.05^{* *} p<=.01$

Table 5. Moderated model slope coefficients for competition intensity on hospital quality

\begin{tabular}{|l|l|l|l|l|l|}
\hline & \multicolumn{1}{|c|}{ Moderator } & \multicolumn{2}{c|}{ Slope*** } & \multicolumn{2}{c|}{ Adjusted R } \\
\hline Independent Variable & Variable & Low & High & Low & High \\
\hline Competition Intensity & Hospital Culture & $.31^{* *}$ & $.46^{* *}$ & $.25^{* *}$ & $.39 * *$ \\
\hline
\end{tabular}

${ }^{* * *}$ Two separate equations were obtained, one for the low (below the median) moderator group, the other for the high (above the median) moderator group. Slope coefficients (non-standardized beta weights) for low and high moderator groups are significantly different (.01 or lower).

${ }^{*} p<=.05,{ }^{* *} p<=.01$

The increment in $\mathrm{R}^{2}$ rather than the magnitude of the correlation coefficient was used to determine the importance of the independent variable in explaining variation in hospital quality (Arnold, 1982; Cohen \& Cohen, 1983). The interaction of the moderating variable and competitions intensity was added, and the increment in $\mathrm{R}^{2}$ (and associated significance level) was determined. This procedure makes the most conservative estimate possible of moderating effects as it "assigns to the additive effects all variance that cannot be unequivocally attributed to the interaction effects" (LaRocco et al., 1980). The interaction is denoted in Table 4 by (Competition Intensity x Competition Intensity).

To avoid the problems associated with subgroup correlational analysis and to complete the moderator model analyses (Arnold, 1982; Peters and Champoux, 1979; Peters et al., 1984), slope coefficients (non-standardized beta coefficients) were used to examine the direction of the significant interactions (Table 5). Furthermore, to determine whether slope coefficients vary as a function of the interaction, the moderator variable was split into low (below the mean values) and high (above the mean values) groups. The statistical significance level of the differences between respective slope coefficients obtained for the two groups (low and high) were tested by applying the formula proposed by Arnold (1982).

\section{DISCUSSION AND RECOMMENDATIONS}

This study's main objectives were to empirically test the relationship between hospital competition intensity as a determinant of hospital quality, and the moderating impact that hospital culture is likely to have on this relationship. While hospital quality has long received considerable attention from researchers and practitioners, the successful test of hypothesis 1 (the relationship between hospital competition intensity and quality) represents a major contribution to knowledge. Another major contribution is the significant impact that hospital organization culture has on this relationship (hypothesis 2). The results provided clear supporting evidence for both hypotheses.

Based on the results hospital administrators should pay greater attention to developing their organizations' culture according to the desirable traits identified in this study. From a Human Resources 
Management perspective, some interesting insights can be derived by looking at the specific items comprising our measures of organization culture. As a whole, they indicate considerable dependence on employees' skills, abilities, and motivation to acquire, process, and manage knowledge as an organization. The employees' ability to use external resources to obtain information (e.g., personal networks, consultants, seminars, internet, databases professional journals, academic publications, market research, laws, and regulations), and their ability to search for relevant information concerning the health care industry (including the hospital, competitors, etc.) which might affect every day and long-term company operations, contributes to a positive organization culture. Managers' ability to motivate employees to use and deal with information sources within and beyond their industry is another significant factor for consideration.

Thus, for hospitals to leverage the connection between the increasingly competitive health care environments, the organization must develop an environment which enables employees to communicate ideas and concepts across departments to solve problems as a group where if a hospital unit obtains important information it communicates such information promptly to all other units in the organization. Besides the normal electronic means of communication, there should be periodical cross-departmental meetings to exchange information on new developments, problems, and achievements. Employees must have the ability to structure and use collected knowledge, and receive training to absorb new knowledge as well as to transfer these new ideas to novel healthcare situations. Last, but perhaps most important, employees must align the new knowledge to the goals and objectives of their jobs, thus enhancing hospital services by regularly reconsidering new processes and new technologies, adapting them to work more effectively.

Given these requirements to improve hospital culture, the Human Resources Management (HRM) sub functions (employee recruiting, retention/weeding out, development/training, performance evaluation, and rewarding) must gain significance in the responsibilities of HRM professionals. These processes must be considered more important strategically, planned and executed more proactively, than the current practice in most hospitals. These HRM sub functions must be revamped and charged with some long-term objectives designed to give the company the people it needs to perform better along the culture traits discussed in this study. Some corporate policy considerations should perhaps start with a deliberate effort to have a stronger HR department whose director reports directly to the $\mathrm{CEO}$ and is an integral member of the corporate executive team. Essential for effective recruiting would be the development of a desirable working environment where intelligent, knowledgeable people want to come to work, rather than viewing people as a commodity whose cost is to be continuously reduced. Last, also probably helpful would be a work environment where workers are empowered to make decisions, are responsible for their results and are given opportunities for promotion from within the organization.

Given the importance of hospital quality, other factors besides competition are likely to be important determinants. For example, two studies have shown that a Board quality committee is a positive factor for improving hospital quality performance, but that fewer than 60 percent of hospitals had them (Jha \& Epstein, 2010; Jiang et al., 2009). Some studies have shown that compensation and performance evaluation based on executive quality performance was related to better quality performance indicators (Jiang et al., 2009; Vaughn et al., 2006), but quality measures were not significant in CEOs' performance evaluation in most cases (Jiang et al., 2008; Joshi \& Hines, 2006). Another important factor related to hospital quality includes interactions between the Board and the medical staff while establishing hospital quality strategy (Vaughn et al., 2006).

Last, a few studies propose that hospital policies encouraging competition are likely to increase healthcare productivity and have a cost-effective result on the quality of medical care (Seiler et al., 2015). To promote competition many possible measures have been proposed including low-cost measures such as giving patients the right to choose, and providing more information regarding hospital performance to the public. The conclusion from these studies is that the benefits from competition should be included in future social cost benefit analyses (Seiler et al., 2015). 


\section{Study Limitations and Future Research Opportunities}

While the constructs studied, and their hypothesized relationships are extremely important in practice, the evidence uncovered and corroborated raises many intriguing research questions. What are some other important determinants of hospital quality? What are some potentially important mediating variables leading to hospital quality and/or other moderating variables affecting their relationships? These represent important research opportunism in this important area of knowledge. 


\section{REFERENCES}

Abbey, A., \& Dickson, J. W. (1983). R\&D work climate and innovation in semiconductors. Academy of Management Journal, 26(2), 362-368.

ANCC, American Nurses Credentialing Center (2017). 2019 Exemplary Professional Practice: Criteria for Nursing Excellence. North Charleston, South: CreateSpace Independent Publishing Platform.

Arnold, H. J. (1982). Moderator variables: A clarification of conceptual, analytic, and psychometric issues. Organizational Behavior and Human Performance, 29(2), 143-174. doi:10.1016/0030-5073(82)90254-9

Baker, G. R., Denis, J.-L., Pomey, M.-P., \& Macintosh-Murray, A. (2010). Effective governance for quality and patient safety in Canadian health care organizations. Ottawa: Canadian Health Services Research Foundation and Canadian Patient Safety Institute.

Balding, C. (2005). Embedding organisational quality improvement through middle manager ownership. International Journal of Health Care Quality Assurance, 18(4), 271-288. doi:10.1108/09526860510602541 PMID:16167642

Berson, Y., Oreg, S., \& Dvir, T. (2008). CEO values, organizational culture and firm outcomes. Journal of Organizational Behavior: The International Journal of Industrial. Occupational and Organizational Psychology and Behavior, 29(5), 615-633. doi:10.1002/job.499

Bhardwaj, S. S., \& Chawla, K. (2013). Exploring competitiveness of the Indian health sector: A service quality perspective. Journal of Health Management, 15(4), 535-547. doi:10.1177/0972063413516225

Bloom, N., Propper, C., Seiler, S., \& Van Reenen, J. (2015). The impact of competition on management quality: Evidence from public hospitals. The Review of Economic Studies, 82(2), 457-489. doi:10.1093/restud/rdu045

Bloom, N., Propper, C., Seiler, S., \& Van Reenen, J. (2015). The impact of competition on management quality: Evidence from public hospitals. The Review of Economic Studies, 82(2), 457-489. doi:10.1093/restud/rdu045

Bradley, E. H., Holmboe, E. S., Mattera, J. A., Roumanis, S. A., Radford, M. J., \& Krumholz, H. M. (2003). The roles of senior management in quality improvement efforts: What are the key components?/Practitioner application. Journal of Healthcare Management, 48(1), 15-28. doi:10.1097/00115514-200301000-00005 PMID:12592866

Bradley, E. H., Webster, T. R., Schlesinger, M., Baker, D., \& Inouye, S. K. (2006). The Roles of Senior Management in Improving Hospital Experiences for Frail Older Adults/PRACTITIONER APPLICATION. Journal of Healthcare Management, 51(5), 323-337. doi:10.1097/00115514-200609000-00009 PMID:17039691

Büschgens, T., Bausch, A., \& Balkin, D. B. (2013). Organizational culture and innovation: A meta-analytic review. Journal of Product Innovation Management, 30(4), 763-781. doi:10.1111/jpim.12021

Carmines, E., \& Zeller, R. (1979). Reliability and Validity Assessment. Beverly Hills, CA: Sage. doi: $10.4135 / 9781412985642$

Chandler, G. N., Keller, C., \& Lyon, D. W. (2000). Unraveling the determinants and consequences of an innovation-supportive organizational culture. Entrepreneurship Theory and Practice, 25(1), 59-76. doi:10.1177/104225870002500106

Chassin, M. R., \& Loeb, J. M. (2013). High-reliability health care: Getting there from here. The Milbank Quarterly, 91(3), 459-490. doi:10.1111/1468-0009.12023 PMID:24028696

Chen, J., Koren, M. E., Munroe, D. J., \& Yao, P. (2014). Is the hospital's magnet status linked to HCAHPS scores? Journal of Nursing Care Quality, 29(4), 327-335. doi:10.1097/NCQ.0000000000000062 PMID:24686041

Cohen, J., \& Cohen, P. (1983). Applied Multiple Regression/Correlation Analysis for the Behavioral Sciences (2nd ed.). Hillsdale, NJ: Lawrence Erlbaum.

Danneels, E. (2008). Organizational antecedents of second-order competences. Strategic Management Journal, 29(5), 519-543. doi:10.1002/smj.684

Davis, S. M. (1984). Managing corporate culture. Cambridge, MA: Ballinger Pub Co. 
Detert, J. R., Schroeder, R. G., \& Mauriel, J. J. (2000). A framework for linking culture and improvement initiatives in organizations. Academy of Management Review, 25(4), 850-863. doi:10.5465/amr.2000.3707740

Everhart, D., Neff, D., Al-Amin, M., Nogle, J., \& Weech-Maldonado, R. (2013). The effects of nurse staffing on hospital financial performance: Competitive versus less competitive markets. Health Care Management Review, 38(2), 146-155. doi:10.1097/HMR.0b013e318257292b PMID:22543824

George, W. R., \& Barksdale, H. C. (1974). Marketing Activities in the Service Industries: An empirical study reveals major differences in the marketing practices of service firms and product firms. Journal of Marketing, $38(4), 65-70$.

Guimaraes, T., Walton, M., \& Armstrong, C. (2018). A New Measure of Organization Culture for Business Innovativeness in Practice. International Journal of the Academic business world, 12(2), 49-58.

Gumusluoğlu, L., \& Ilsev, A. (2009). Transformational leadership and organizational innovation: The roles of internal and external support for innovation. Journal of Product Innovation Management, 26(3), 264-277. doi:10.1111/j.1540-5885.2009.00657.x

Gupta, K. S., \& Rokade, V. (2016). Importance of quality in health care sector: A review. Journal of Health Management, 18(1), 84-94. doi:10.1177/0972063415625527

Hartnell, C. A., Ou, A. Y., \& Kinicki, A. (2011). Organizational culture and organizational effectiveness: A meta-analytic investigation of the competing values framework's theoretical suppositions. The Journal of Applied Psychology, 96(4), 677-694. doi:10.1037/a0021987 PMID:21244127

Hurley, R. F., \& Hult, G. T. M. (1998). Innovation, market orientation, and organizational learning: An integration and empirical examination. Journal of Marketing, 62(3), 42-54. doi:10.1177/002224299806200303

Igbaria, M., Greenhaus, J. H., \& Parasuraman, S. (1991). Career orientations of MIS employees: An empirical analysis. Management Information Systems Quarterly, 15(2), 151-169. doi:10.2307/249376

Jaskyte, K. (2004). Transformational leadership, organizational culture, and innovativeness in nonprofit organizations. Nonprofit Management \& Leadership, 15(2), 153-168. doi:10.1002/nml.59

Jaworski, B. J., \& Kohli, A. K. (1993). Market orientation: Antecedents and consequences. Journal of Marketing, 57(3), 53-70. doi:10.1177/002224299305700304

Jha, A., \& Epstein, A. (2010). Hospital governance and the quality of care. Health Affairs, 29(1), 182-187. doi:10.1377/hlthaff.2009.0297 PMID:19897509

Jha, A. K., Orav, E. J., Li, Z., \& Epstein, A. M. (2007). The inverse relationship between mortality rates and performance in the Hospital Quality Alliance measures. Health Affairs, 26(4), 1104-1110. doi:10.1377/ hlthaff.26.4.1104 PMID:17630453

Jiang, H. J., Lockee, C., Bass, K., \& Fraser, I. (2008). Board engagement in quality: Findings of a survey of hospital and system leaders. Journal of Healthcare Management, 53(2), 121-134. doi:10.1097/00115514200803000-00009 PMID:18421996

Jiang, H. J., Lockee, C., Bass, K., \& Fraser, I. (2009). Board oversight of quality: Any differences in process of care and mortality? Journal of Healthcare Management, 54(1), 15-29. doi:10.1097/00115514-20090100000005 PMID:19227851

Joshi, M. S., \& Hines, S. C. (2006). Getting the board on board: Engaging hospital boards in quality and patient safety. Joint Commission Journal on Quality and Patient Safety, 32(4), 179-187. doi:10.1016/S15537250(06)32023-5 PMID:16649648

Kwieciński, D. (2017). Measures of Competitive Intensity-Analysis Based on Literature Review. Journal of Management and Business Administration, 25(1), 53-77.

LaRocco, J. M., House, J. S., \& French, J. R. P. (1980). Social support, occupational stress and health. Journal of Health and Social Behavior, 21(3), 202-218. doi:10.2307/2136616 PMID:7410798

Lasater, K. B., Germack, H. D., Small, D. S., \& McHugh, M. D. (2016). Hospitals known for nursing excellence perform better on value based purchasing measures. Policy, Politics \& Nursing Practice, 17(40), 177-186. doi:10.1177/1527154417698144 PMID:28558604 
Levey, S., Vaughn, T., Koepke, M., Moore, D., Lehrman, W., \& Sinha, S. (2007). Hospital leadership and quality improvement: Rhetoric versus reality. Journal of Patient Safety, 3(1), 9-15. doi:10.1097/PTS.0b013e3180311256

Lindenauer, P. K., Remus, D., Roman, S., Rothberg, M. B., Benjamin, E. M., Ma, A., \& Bratzler, D. W. (2007). Public reporting and pay for performance in hospital quality improvement. The New England Journal of Medicine, 356(5), 486-496. doi:10.1056/NEJMsa064964 PMID:17259444

Lush, R. F., \& Laczniak, G. R. (1987). The evolving marketing concept, competitive intensity and organisational performance. Journal of the Academy of Marketing Science, 15(3), 1-11. doi:10.1007/BF02722166

Magal, S. R., Carr, H. H., \& Watson, H. J. (1988). Critical success factors for information center managers. Management Information Systems Quarterly, 12(3), 413-425. doi:10.2307/249208

Mastal, M. F., Joshi, M., \& Schulke, K. (2007). Nursing leadership: Championing quality and patient safety in the boardroom. Nursing Economics, 25(6), 323-332. PMID:18240833

Mehta, S. (2011). Service quality as predicator of patient satisfaction: A study of the health care sector. Journal of Health Management, 13(2), 211-229. doi:10.1177/097206341101300206

Missios, S., \& Bekelis, K. (2018). Association of hospitalization for neurosurgical operations in magnet hospitals with mortality and length of stay. Neurosurgery, 82(3), 372-377. doi:10.1093/neuros/nyx203 PMID:28472336

Montgomery, A., Todorova, I., Baban, A., \& Panagopoulou, E. (2013). Improving quality and safety in the hospital: The link between organizational culture, burnout, and quality of care. British Journal of Health Psychology, 18(3), 656-662. doi:10.1111/bjhp.12045 PMID:23607495

Nunnally, J. C. (1978). Psychometric Theory. New York, NY: McGraw-Hill.

Ogbonna, E., \& Wilkinson, B. (2003). The false promise of organizational culture change: A case study of middle managers in grocery retailing. Journal of Management Studies, 40(5), 1151-1178. doi:10.1111/1467-6486.00375

Parand, A., Dopson, S., Renz, A., \& Vincent, C. (2014). The role of hospital managers in quality and patient safety: A systematic review. BMJ Open, 4(9), e005055. doi:10.1136/bmjopen-2014-005055 PMID:25192876

Park, S. H., Gass, S., \& Boyle, D. K. (2016). Comparison of reasons for nurse turnover in Magnet ${ }^{\circledR}$ and nonMagnet hospitals. The Journal of Nursing Administration, 46(5), 284-290. PMID:27093185

Peters, L. H., O'Connor, E. J., \& Wise, S. L. (1984). The specification and testing of useful moderator variable hypotheses. In T. S. Bateman \& G. R. Ferris (Eds.), Method and Analysis in Organizational Research (pp. 128-139). Reston, VA: Reston Publishing.

Peters, T. J., \& Waterman, R. H. (1982). In Search of Excellence: Lessons from America's Best-Run Companies. New York, NY: Harper \& Row.

Peters, W. S., \& Champoux, J. E. (1979). The use of moderated regression in job redesign Decisions. Decision Sciences, 10(1), 85-95. doi:10.1111/j.1540-5915.1979.tb00009.x

Peterson, R. A. (1994). A meta-analysis of Cronbach's coefficient alpha. The Journal of Consumer Research, 21(2), 381-391. doi:10.1086/209405

Poniatowski, L., Stanley, S., \& Youngberg, B. (2005). Using information to empower nurse managers to become champions for patient safety. Nursing Administration Quarterly, 29(1), 72-77. doi:10.1097/00006216-20050100000012 PMID: 15779708

Prybil, L. D., Peterson, R., Brezinski, P., Zamba, G., Roach, W. Jr, \& Fillmore, A. (2010). Board oversight of patient care quality in community health systems. American Journal of Medical Quality, 25(1), 34-41. doi:10.1177/1062860609352804 PMID:20042764

Sackmann, S. A. (2011). Culture and performance. In N. Ashkansay, C. Wilderom, \& M. Peterson (Eds.), The handbook of organizational culture and climate (2nd ed., pp. 188-224). Thousand Oaks, CA: SAGE. doi:10.4135/9781483307961.n12

Saint, S., Kowalski, C. P., Banaszak-Holl, J., Forman, J., Damschroder, L., \& Krein, S. L. (2010). The importance of leadership in preventing healthcare-associated infection: Results of a multisite qualitative study. Infection Control and Hospital Epidemiology, 31(9), 901-907. doi:10.1086/655459 PMID:20658939 
Schneider, B., Ehrhart, M. G., \& Macey, W. H. (2013). Organizational climate and culture. Annual Review of Psychology, 64(1), 361-388. doi:10.1146/annurev-psych-113011-143809 PMID:22856467

Sharma, J. K., \& Narang, R. (2011). Quality of healthcare services in rural India: The user perspective. Vikalpa, 36(1), 51-60. doi:10.1177/0256090920110104

Srinivasan, A. (1985). Alternative measures of system effectiveness: Associations and implications. Management Information Systems Quarterly, 9(3), 243-253. doi:10.2307/248951

Stimpfel, A. W., Rosen, J. E., \& McHugh, M. D. (2014). Understanding the role of the professional practice environment on quality of care in Magnet and non-Magnet hospitals. The Journal of Nursing Administration, 44(1), 10-16. doi:10.1097/NNA.0000000000000015 PMID:24316613

Stimpfel, A. W., Sloane, D. M., McHugh, M. D., \& Aiken, L. H. (2016). Hospitals known for nursing excellence associated with better hospital experience for patients. Health Services Research, 51(3), 1120-1134. doi:10.1111/1475-6773.12357 PMID:26369862

Teo, T. S., \& King, W. R. (1996). Assessing the impact of integrating business planning and IS planning. Information \& Management, 30(6), 309-321. doi:10.1016/S0378-7206(96)01076-2

The Truth About Nursing. (2016). Magnet status: What it is, what it is not, and what it could be. Retrieved from https://www.truthaboutnursing.org/faq/magnet.html

Van de Ven, A., \& Ferry, D. (1980). Measuring and Assessing Organizations. New York, NY: Wiley.

Vaughn, T., Koepke, M., Kroch, E., Lehrman, W., Sinha, S., \& Levey, S. (2006). Engagement of leadership in quality improvement initiatives: Executive quality improvement survey results. Journal of Patient Safety, 2(1), $2-9$.

Verelst, S., Jacques, J., Van den Heede, K., Gillet, P., Kolh, P., Vleugels, A., \& Sermeus, W. (2012). Retrospective medical record evaluation: Reliability in assessing causation, preventability, and disability of adverse events. International Journal of Health Care Quality Assurance, 25(8), 649-662. doi:10.1108/09526861211270613 PMID:23276060

Wei, Y., \& Morgan, N. A. (2004). Supportiveness of organizational climate, market orientation, and new product performance in Chinese firms. Journal of Product Innovation Management, 21(6), 375-388. doi:10.1111/j.07376782.2004.00092.x

Weingart, S. N., \& Page, D. (2004). Implications for practice: Challenges for healthcare leaders in fostering patient safety. BMJ Quality \& Safety, 13(suppl 2), ii52-ii56. doi:10.1136/qshc.2003.009621 PMID:15576693

Wilde-Larsson, B., \& Larsson, G. (2009). Patients' views on quality of care and attitudes towards re-visiting providers. International Journal of Health Care Quality Assurance, 22(6), 600-611. doi:10.1108/09526860910986867 PMID:19957421

Zedeck, S. (1971). Problems with the use of "moderator" variables. Psychological Bulletin, 76(4), 295-310. doi: $10.1037 / \mathrm{h} 0031543$ 


\section{APPENDIX A}

10. We use metrics on our creative and development processes to track how much time and money is spent on creating and implementing innovation.

Table 6.

\begin{tabular}{|l|l|}
\hline $\begin{array}{l}\text { Measuring Competition Intensity: Please rate your hospital competitive environment along the items below using } \\
\text { the scale (1) not at all, (2) to a minor extent, (3) to some extent, (4) to a major extent, (5) to a great extent. }\end{array}$ \\
\hline 1. Competition in our geographical area is cutthroat. & 12345 \\
\hline 2. There are many "promotion wars" affecting us. & 12345 \\
\hline 3. Anything that one competitor can offer others can readily match. & 12345 \\
\hline 4. Competition is the hallmark for us. & 12345 \\
\hline 5. One hears of a new competitive move very often. & 12345 \\
\hline 6. Our competitors are relatively weak. & 12345 \\
\hline 7. Due to increased competition we will be spending more for marketing. & 12345 \\
\hline 8. We will be fighting aggressively to hold on to our share of the market. & 12345 \\
\hline 9. Competition will be more intense. & 12345 \\
\hline
\end{tabular}

Table 7.

Measuring Organization Culture Traits: Please rate the extent to which your company shows the specific culture trait listed below, using the scale: $0=I$ don't know, $1=$ not at all, $2=$ a minor extent, $3=$ some extent, $4=a$ significant extent, $5=$ major extent, and $6=$ a great extent.

1. People in this organization have a sense of direction, a vision for its future, with clearly defined goals, objectives, and responsibilities.

2.People are tuned in to what is going on in the market place regarding customers, competitors and their products/services, suppliers, etc.

\begin{tabular}{|l|l|}
\hline 3. New ideas are encouraged and seriously evaluated. & 0123456 \\
\hline $\begin{array}{l}\text { 4. People in this organization have a sense of direction, a vision for its future, with clearly defined } \\
\text { goals, objectives, and responsibilities. }\end{array}$ & 0123456 \\
\hline 5. Goals and tasks assignments are discussed and agreed to by the people involved. & 0123456 \\
\hline 6. The goals set are challenging but attainable. & 0123456 \\
\hline 7. People are accountable for what they agreed to do. & 0123456 \\
\hline 8. People are willing to personally sacrifice a little to accomplish their tasks and goals. & 0123456 \\
\hline 9. People are rewarded for good performance toward their goals. & 0123456 \\
\hline $\begin{array}{l}\text { 10. We use metrics on our creative and development processes to track how much time and money } \\
\text { is spent on creating and implementing innovation. }\end{array}$ & 0123456 \\
\hline 11. In this organization, employees trust each other, communicate and cooperate freely. & 0123456 \\
\hline 12. There is a good balance between specialization and ability to step in to do someone else's work. & 0123456 \\
\hline
\end{tabular}




\section{6}

11. In this organization, employees trust each other, communicate and cooperate freely. 0123456

12. There is a good balance between specialization and ability to step in to do someone else's work. 0123456

13.In this organization employees trust their superiors.

0123456

Measuring Hospital Quality: Compared with its main competitors, please rate you hospital along the items below using the scale (1) much worse, (2) significantly worse, (3) slightly worse, (4) about even, (5) slightly better, (6) significantly better, and (7) much better.

1. Overall patient care.

\section{7}

2. Infection control effectiveness.

1234567

3. Overall hospital environment (cleanliness, attractiveness, safety, security, etc.).

1234567

4. Quality of medical services (physicians and staff performance).

1234567

5. Standard operating procedures.

1234567

6. Responsiveness of service.

1234567

7. Patient complaints rate.

1234567

8. Resolution of patient complaints.

1234567

9. Overall hospital image.

1234567 
Tor Guimaraes has been rated by several independent sources as one of the top researchers in the world based on publications in the top IS journals. He holds the Jesse E. Owen Chair of Excellence at Tennessee Technological University. He has been the keynote speaker at numerous national and international meetings sponsored by organizations such as the Information Processing Society of Japan, Institute of Industrial Engineers, Sales and Marketing Executives, IEEE, Association for Systems Management, and the American Society for Quality Control. Tor has consulted with many leading organizations including TRW, American Greetings, AT\&T, IBM and the Department of Defense.

Maria do Carmo Caccia-Bava has a PhD in Public Health from the University of Sao Paulo. She is a Professor of Public Health Management at the University of Sao Paulo School of Medicine, in Ribeirao Preto which has been rated as one of the top Medical Schools in Latin America. She has been the Director of the Medical School's Health Center, where approximately 120.000 health procedures are delivered each year, and where over a thousand students study and practice in the areas of Medicine, Nursing, Physiotherapy, Dentistry, Pharmacology and Psychology. She works closely with the Family Health Program, managing services, doing research, and making presentations about new technologies in primary care. She is presently a member of the research team assessing the quality of primary care in Brazil's Southeast region for the Ministry of Health.

Melissa Geist, Dr., is a Professor of Nursing as well as a practicing board-certified nurse practitioner. Dr. Geist received her doctorate at Peabody College of Vanderbilt University. She completed a Post-Doctoral Fellowship with the NSF funded VaNTH Engineering Research Center where she developed and implemented legacy cycles as part of curricular reformation in Biomedical Engineering aimed at increasing flexible knowledge and adaptive expertise of students. She has received the outstanding faculty award and the award for innovative instruction as part of the university quality enhancement program. 